\title{
End-Functional Styrene-Maleic Anhydride Copolymers via Catalytic Chain Transfer Polymerization
}

\author{
Gemma C. Sanders, ${ }^{\dagger \ddagger}$ Robbert Duchateau, ${ }^{\dagger}$ Ching Yeh Lin, ${ }^{\S}$ Michelle L. Coote, ${ }^{\S}$ \\ and Johan P. A. Heuts ${ }^{\dagger} *$ \\ ${ }^{\dagger}$ Laboratory of Polymer Chemistry, Eindhoven University of Technology, P.O. Box 513, 5600 MB Eindhoven, The Netherlands \\ ${ }^{\ddagger}$ Dutch Polymer Institute (DPI), John F. Kennedylaan 2, 5612 AB Eindhoven, The Netherlands \\ ${ }^{\S}$ ARC Centre of Excellence for Free-Radical Chemistry and Biotechnology, Research School of Chemistry, Australian National \\ University, Canberra, ACT 0200, Australia
}

\section{Supporting Information}

\begin{abstract}
Styrene-maleic anhydride copolymers have been successfully synthesized using catalytic chain transfer polymerization employing the low spin [bis(difluoroboryl)dimethylglyoximato]cobalt(II) (COBF) complex. By partially replacing styrene with $\alpha$-methylstyrene (while maintaining the amount of maleic anhydride at $50 \mathrm{~mol} \%$ ) over a range of ratios, it was shown that the rate of reaction and molar mass decreases with increasing $\alpha$-methylstyrene content. The polymers were characterized using MALDI-ToF-MS and ${ }^{1} \mathrm{H}-{ }^{13} \mathrm{C}$ gHMQC NMR to determine the end groups, which in the presence of $\alpha$-methylstyrene was an $\alpha$-methylstyrene unit with a vinylic functionality. For styrene-maleic anhydride copolymers, the end group was determined to be predom-

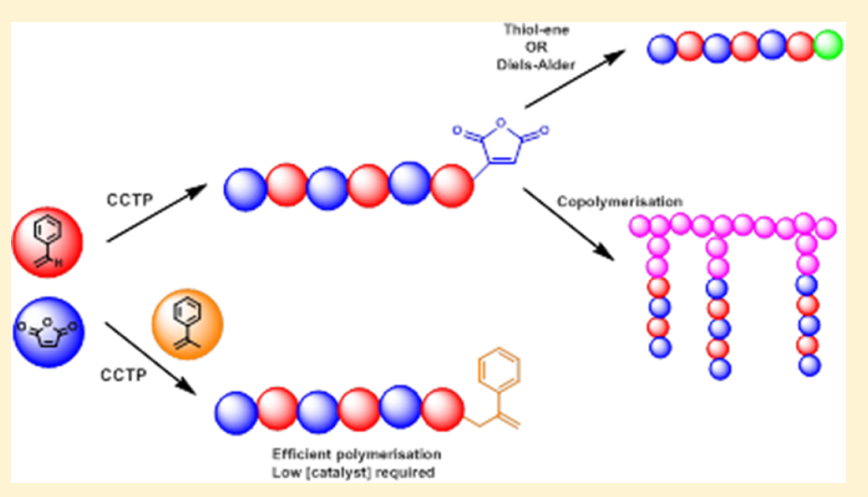
inantly maleic anhydride with a vinylic functionality. Considering the fact that in a styrene-maleic anhydride copolymerization the propagating radicals are predominantly of a styrenic nature, this was a very surprising result, suggesting that the maleic anhydride radicals undergo a chain transfer reaction, which is orders of magnitude faster than that of styrenic radicals. This conclusion was supported by high-level $a b$ initio quantum chemical calculations, which showed that hydrogen abstraction from the maleic anhydride radical is $40 \mathrm{~kJ} / \mathrm{mol}$ more exothermic than that from a styrene radical. The chain transfer constant of COBF was determined for the different ratios of styrene and $\alpha$-methylstyrene. It was found to increase 2 orders of magnitude from a purely styrene-maleic anhydride to a purely $\alpha$-methylstyrene-maleic anhydride copolymer. Diels-Alder and thiol-ene reactions were performed on the vinylic end groups as postpolymerization modification reactions, as well as graft copolymerization reactions of the macromonomers with styrene and butyl acrylate.
\end{abstract}

\section{INTRODUCTION}

Styrene-maleic anhydride copolymers (pSMA) are used extensively in applications such as engineering plastics, surfactants in the paper-making industry and as polymerprotein conjugates for drug delivery systems. ${ }^{1}$ The versatility of these polymers lies within their properties, which include transparency, a high heat resistance, high dimensional stability, and the specific reactivity of the anhydride groups. To fulfill these varying roles, pSMA copolymers come in a range of molar masses and compositions.

The kinetics of their polymerization has also been studied at length. ${ }^{2}$ Maleic anhydride (MAh) does not homopolymerise, however in the presence of styrene $(\mathrm{S})$, a highly reactive system is created, resulting in an almost perfectly alternating polymer. ${ }^{3}$ Although most work relating to pSMA copolymers has been via the conventional free radical route, efforts have been made recently to investigate and evaluate the possibility of polymerizing pSMA using controlled radical routes. Atom transfer radical polymerization (ATRP) is incompatible with SMA copolymerization due to interactions between MAh and the catalysts used to mediate these reactions. ${ }^{2}$ Nitroxide-mediated polymerization (NMP) has also been used to copolymerise $S$ and MAh but a temperature of over $80{ }^{\circ} \mathrm{C}$ is required. ${ }^{4}$ This is the upper temperature limit to generate perfectly alternating copolymers and thus control over the sequence is more difficult. Reversible addition-fragmentation chain transfer polymerization (RAFT) was more successful at synthesizing pSMA copolymers, at lower (and thus optimal) temperatures. ${ }^{5}$ The obvious advantage of using a controlled radical polymerization method over conventional free radical polymerization is the ability to control the molar mass as well as synthesizing monodisperse polymers,

Received: June 7, 2012

Revised: July 5, 2012

Published: July 23, 2012 
all with a specific end group. Although these methods are very effective, their industrial application still seems to be limited.

Catalytic chain transfer polymerization (CCTP), ${ }^{6}$ on the other hand, is already used widely in the coating industry as a route to reducing the volatile organic compound (VOC) content of coatings. ${ }^{7}$ CCTP is a very effective route to synthesizing polymers with vinyl functionalities. ${ }^{6}$ The addition of very small quantities of certain low-spin $\mathrm{Co}^{\mathrm{II}}$ catalysts, such as [bis(difluoroboryl)dimethylglyoximato]cobalt(II) (COBF), to a conventional free radical polymerization results in two major effects. First, the molar mass of the polymer chains is controlled via a chain transfer mechanism, and second, due to the mechanism of the chain transfer process, vinylic end groups can be obtained. The cobalt catalyst abstracts a hydrogen atom from the growing polymer chain, transferring it to a monomer molecule, thus starting a new chain and reducing the cobalt back to $\mathrm{Co}^{\mathrm{II}}$. Although this process is highly efficient for methacrylate monomers, it is about 2 orders of magnitude slower for styrene. First, styrene interacts with COBF to form strong $\mathrm{Co}-\mathrm{C}$ bonds, reducing the efficiency of the catalyst and second styrene has no methyl group in the $\beta$-position, and thus a backbone hydrogen is instead preferentially abstracted. This results in an "internal" double bond, which is less reactive in any possible further postpolymerization reactions. The drawbacks of an inefficient chain transfer process and the absence of "external" double bonds in styrene polymerization can be overcome by the addition of small amounts of $\alpha$-methylstyrene (AMS) as has been discussed in detail previously. ${ }^{6 c, 8}$ Since in a SMA copolymerization the propagating radical population is dominated by $S$ radicals, ${ }^{2}$ it can be anticipated that addition of AMS to this copolymerization will improve the chain transfer efficiency and lead to the introduction of AMS end groups.

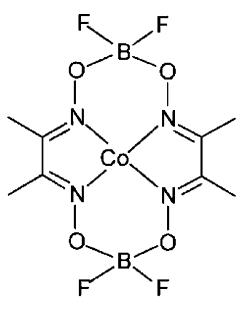

COBF

In the present article, we investigate whether vinyl endfunctional pSMA can be synthesized efficiently using CCTP and whether the addition of AMS indeed makes the process more efficient. In what follows we discuss the chain transfer kinetics using varying amounts of AMS, we fully characterize the polymer structures and support our experimental findings of the formed end groups by $a b$ initio quantum chemical calculations. Finally the scope of postpolymerization reactions is discussed.

\section{EXPERIMENTAL AND COMPUTATIONAL DETAILS}

General Considerations. All syntheses and manipulations of airand moisture-sensitive materials were carried out in oven-dried Schlenk-type glassware on a dual manifold Schlenk line.

Materials. Styrene (S, 99\%), $\alpha$-methylstyrene (AMS, 99\%) and tert-butyl acrylate (BA, 98\%) were purchased from Sigma-Aldrich, and passed over a column of activated basic alumina to remove the inhibitor. Maleic anhydride (MAh, 99\%) was purchased from SigmaAldrich and used as received. Azobis(isobutryonitrile) (AIBN) and Vazo-88 were purchased from Sigma-Aldrich and recrystallized twice from methanol. The bis(methanol) complex of COBF, was prepared as described previously. ${ }^{9 \mathrm{a}, \mathrm{b}}$ The chain transfer constant of the complex was determined in methyl methacrylate (MMA) bulk polymerization and found to be equal to $30 \times 10^{3}$. For all experiments, a single batch of catalyst was used. 1,4-Dioxane (AR, Biosolve) was used as received for conversion measurements but distilled and stored in the fridge for chain transfer determination experiments.

Typical Procedure for the Copolymerization of Styrene, Maleic Anhydride, and $\alpha$-Methylstyrene in the Presence of COBF. COBF $(2.7 \mathrm{mg}, 6.8 \mu \mathrm{mol})$, AIBN ( $42 \mathrm{mg}, 0.25 \mathrm{mmol}$ ), and MAh (25 g, $0.26 \mathrm{~mol})$ were placed in a flask equipped with a stirrer bar and underwent three vacuum-argon cycles. $S$ ( $26 \mathrm{~mL}, 0.23 \mathrm{~mol})$, AMS $(3.3 \mathrm{~mL}, 0.03 \mathrm{~mol})$ and 1,4-dioxane $(50 \mathrm{~mL})$ were degassed and added using a syringe. The mixture was heated to $60{ }^{\circ} \mathrm{C}$ and allowed to react for $7 \mathrm{~h}$. The reaction mixture was quenched by cooling in ice and addition of hydroquinone. The residual (liquid) monomers and solvent were removed via vacuum evaporation immediately after stopping the reaction. The resulting polymer was redissolved in THF and precipitated in a large excess of diethyl ether, then dried in a vacuum oven at $80^{\circ} \mathrm{C}$ for at least $48 \mathrm{~h}$.

Typical Procedure for the Determination of Chain Transfer Constants. Two stock solutions were made. COBF $(30 \mathrm{mg}, 75 \mu \mathrm{mol})$ was dissolved in $30 \mathrm{~mL}$ distilled dioxane. AIBN $(20 \mathrm{mg}, 122 \mu \mathrm{mol})$, AMS (1.5 mL, $11.6 \mathrm{mmol})$, and MAh (13.5 g, $1.38 \mathrm{~mol}$ ) were dissolved in $18 \mathrm{~mL}$ of distilled dioxane. To each finger Schlenk, the appropriate amount of COBF solution (made up to $1 \mathrm{~mL}$ with distilled dioxane), $3 \mathrm{~mL}$ of the AIBN/AMS/MAh solution is added and finally $S(2.0 \mathrm{~mL}, 17.4 \mathrm{mmol})$ is added (S kept separate from AIBN solution, as some evidence of conventional FRP is seen when they are combined). The finger Schlenks underwent three freezepump-thaw cycles and were then placed in an oil bath preheated to $60{ }^{\circ} \mathrm{C}$. After $15 \mathrm{~min}$, the reaction mixture was cooled in ice and hydroquinone added to quench the reaction.

Diels-Alder Coupling of pSMA with Danishefsky's Diene. A 2000 Da pSMA (0.1 g, $75 \mu \mathrm{mol})$ and Danishefsky's diene (trans-1methoxy-3-trimethylsiloxy-1,3-butadiene, $375 \mu \mathrm{mol}$ ) were dissolved in $3 \mathrm{~mL}$ xylene in a crimp cap vial. The vial was then placed in an oil bath and the temperature increased to $180{ }^{\circ} \mathrm{C}$. The reaction was stirred at this temperature for 6 days.

Thiol-Ene Reaction of Citraconic Anhydride with Dodecanethiol. Citraconic anhydride $(0.1 \mathrm{~g}, 0.9 \mathrm{mmol})$ and dodecanethiol $(0.18 \mathrm{~g}, 0.9 \mathrm{mmol})$ were dissolved in $0.5 \mathrm{~mL}$ of $\mathrm{CDCl}_{3}$ in an NMR tube equipped with a screw cap. $\mathrm{N}_{2}$ was bubbled through for $10 \mathrm{~min}$ prior to the reaction. DMPP $(10 \mu \mathrm{L}, 0.07 \mu \mathrm{mol})$ was then added via syringe and the reaction allowed to stir at room temperature overnight.

Thiol-Ene Reaction of pSMA with Octanethiol. A $2000 \mathrm{Da}$ pSMA $(0.1 \mathrm{~g}, 75 \mu \mathrm{mol})$ and octanethiol $(0.02 \mathrm{~g}, 150 \mu \mathrm{mol})$ were dissolved in $2 \mathrm{~mL}$ of acetone. $\mathrm{N}_{2}$ was bubbled through for $10 \mathrm{~min}$ prior to the reaction. DMPP $(10 \mu \mathrm{L}, 75 \mu \mathrm{mol})$ was then added via syringe and the reaction allowed to stir at room temperature overnight.

Typical Procedure for the Graft Copolymerization of pSMA. A 4000 Da pSMA $(0.5 \mathrm{~g}, 125 \mu \mathrm{mol}), \mathrm{S}(0.46 \mathrm{~g}, 4.4 \mathrm{mmol})$, Vazo- 88 (0.05 wt \% of monomer and macromonomer), and dioxane $(2.7 \mathrm{~g})$ were weighed into a crimp cap vial. The solution was stirred until a clear solution was obtained, then argon was bubbled through for 15 $\mathrm{min}$. The vial was then placed in an oil bath at $60{ }^{\circ} \mathrm{C}$ for 4 days. The resulting polymer solution was then quenched by cooling in ice and addition of hydroquinone. Residual monomer and solvent were removed under vacuum at elevated temperatures.

Typical Procedure Graft Copolymerization of pASMA. A 1200 Da pASMA (0.5 g, $417 \mu \mathrm{mol}), \mathrm{S}(1.0 \mathrm{~g}, 9.6 \mathrm{mmol})$, Vazo- 88 ( $0.05 \mathrm{wt} \%$ of monomer and macromonomer), and dioxane $(6 \mathrm{~g})$ were weighed into a crimp cap vial. The solution was stirred until a clear solution was obtained then argon was bubbled through for $15 \mathrm{~min}$. The vial was then placed in an oil bath at $60{ }^{\circ} \mathrm{C}$ for 4 days. The resulting polymer solution was then quenched by cooling in ice and addition of hydroquinone. Residual monomer and solvent were removed under vacuum at elevated temperatures.

Measurements. Size exclusion chromatography was carried out using a Waters 2695 separations module, Model 2487 UV detector $(254 \mathrm{~nm})$, and Model 2414 differential refractive index detector (40 $\left.{ }^{\circ} \mathrm{C}\right)$. The injection volume used was $50 \mu \mathrm{L}$. Tetrahydrofuran 

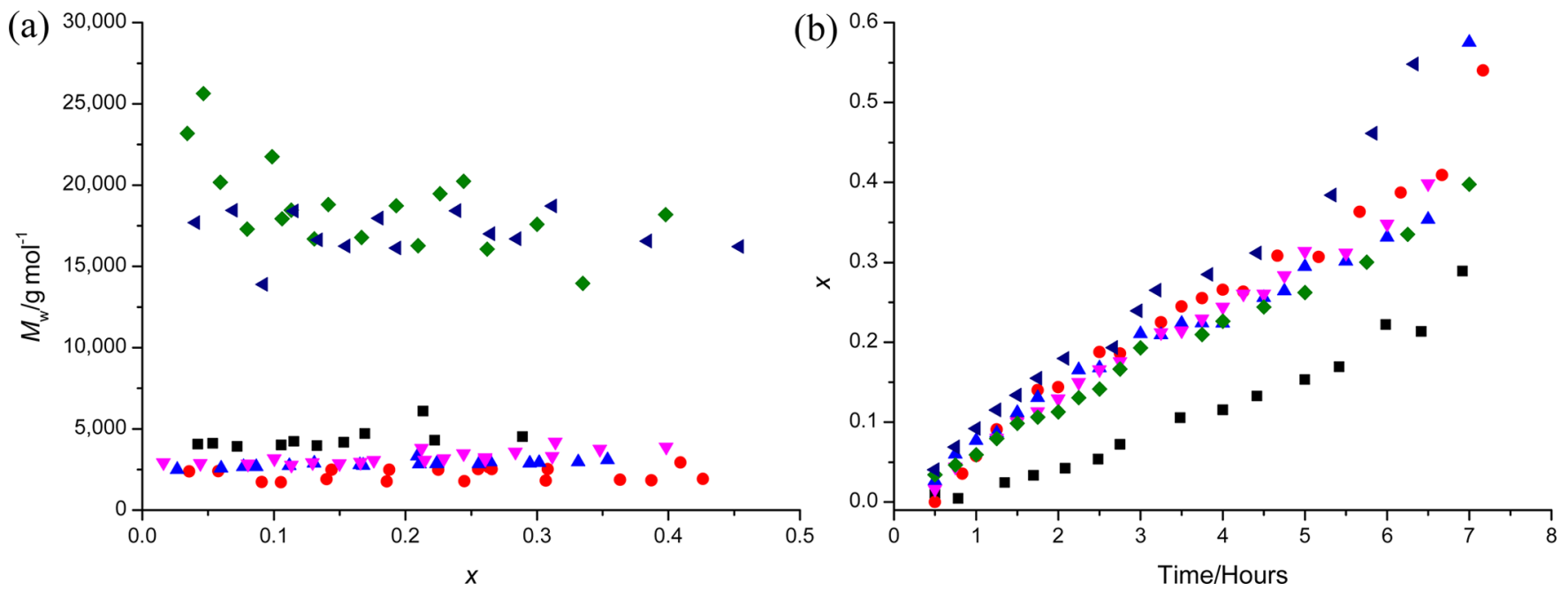

Figure 1. Effect of catalyst loading on (a) molar mass evolutions and (b) conversion $(x)$ vs time plots for the COBF-mediated free-radical polymerization of S/AMS/MAh $(45 / 5 / 50)$ at $60{ }^{\circ} \mathrm{C}$ in undistilled dioxane. $[\mathrm{COBF}]=456 \mathrm{ppm}(\boldsymbol{\square}), 91 \mathrm{ppm}(\mathrm{red} \boldsymbol{\bullet}), 32 \mathrm{ppm}(\mathrm{blue} \boldsymbol{\Delta}), 23 \mathrm{ppm}$ (pink $\boldsymbol{\nabla}), 9$ ppm (green $\diamond), 6$ ppm $(\langle)$.

(Biosolve, stabilized with $\mathrm{BHT}$ ) was used as the eluent with a flow rate $1.0 \mathrm{~mL} / \mathrm{min}$. The column set used was a PLgel guard ( $5 \mu \mathrm{m}$ particles) $50 \times 7.5 \mathrm{~mm}$ precolumn, followed by 2 PLgel columns in series of 500 $\AA$ (5 $\mu \mathrm{m}$ particles $)$ and $100 \AA(5 \mu \mathrm{m}$ particles $)$ respectively. Calibration was performed using polystyrene standards (Polymer Laboratories, $M_{\mathrm{n}}=370$ up to $M_{\mathrm{n}}=40000 \mathrm{~g} / \mathrm{mol}$ ). Reported molar mass data have been corrected using the following Mark-HouwinkKuhn-Sakurada constants: $K_{\mathrm{pS}}=1.28 \times 10^{-4} \mathrm{dL} \cdot \mathrm{g}^{-1}, a_{\mathrm{pS}}=0.712{ }^{9 \mathrm{c}}$ $K_{\mathrm{pSMA}}=5.07 \times 10^{-5} \mathrm{dL} \cdot \mathrm{g}^{-1}, a_{\mathrm{pSMA}}=0.81 .^{9 \mathrm{~d}}$ Data acquisition and processing were performed using Waters Empower 2 software. ${ }^{1} \mathrm{H},{ }^{13} \mathrm{C}$ and gHMQC NMR spectra were recorded on a Varian Mercury Vx $(400 \mathrm{MHz})$ spectrometer at $400 \mathrm{MHz}$. Acetone- $d_{6}$ or chloroform- $d_{3}$ and tetramethylsilane were used as solvents and internal standard, respectively. MALDI-ToF-MS was carried out using an Applied Biosystems Voyager DE-STR spectrometer in reflector mode. trans-2(3-(4-tert-Butylphenyl)-methyl-2-propenylidene)malononitrile doped with potassium trifluoroacetate was used as the matrix. The mixture was deposited from a THF solution onto a stainless steel sample substrate and the solvent allowed to evaporate. The polymer was then deposited as a dilute $(\sim 1 \mathrm{mg} / \mathrm{mL})$ solution in THF. This resulted in each polymeric species being observed as its $\mathrm{K}^{+}$adduct with molecular mass $M+31$. The spectrometer was calibrated using poly(ethylene oxide) standards for the lower mass range and polystyrene standards for the higher mass range.

Computational Details. Standard $a b$ initio molecular orbital theory and density functional theory calculations were performed using Gaussian $09^{10}$ and Molpro 2009.1 ${ }^{11}$ software, using a high-level of theory, previously shown to reproduce bond dissociation energies and associated hydrogen transfer reaction energies to within chemical accuracy. ${ }^{12}$ Geometries of all species were optimized at the B3-LYP/6$31 \mathrm{G}(\mathrm{d})$ level of theory and scaled frequency calculations were also performed at that level; this level has been previously shown to reproduce geometries and frequencies obtained via high-level $a b$ initio methods. ${ }^{2 b, 13}$ All possible stereoisomers and conformers of the reactants were fully searched at this level of theory to ensure that global minima rather than merely local minima were obtained. Improved energies were then obtained using the G3(MP2)-RAD method. ${ }^{14}$ Partition functions and associated thermodynamic quantities at $298.15 \mathrm{~K}$ were calculated using the standard textbook formulas for an ideal gas under the rigid-rotor/harmonic oscillator approximation.

\section{RESULTS AND DISCUSSION}

Synthesis of ASMA and SMA Copolymers. Copolymers of $\alpha$-methylstyrene (AMS), styrene (S), and maleic anhydride
(MAh) have been synthesized in the presence of varying amounts of $\mathrm{COBF}$ at a reaction temperature of $60{ }^{\circ} \mathrm{C}$. In a series of reactions $10 \% \mathrm{~S}$ was replaced with AMS, maintaining equimolar ratios of styrenic monomers $(\mathrm{S}+\mathrm{AMS})$ to maleic anhydride. The molar mass evolutions and polymerization kinetics of these reactions with respect to the concentration of COBF were investigated and as seen in Figure 1, there was a clear influence of $\mathrm{COBF}$ concentration on the molar mass of the polymer. As expected, with increasing [COBF], the molar mass of the polymers decreased. In addition, the molar mass of the polymers remained fairly constant throughout the reaction, which seems to be a generally observed (but still not understood) phenomenon in CCTP. ${ }^{6 c, d, 15}$

From Figure 1 it is also clear that COBF has negligible effect on the rate of polymerization; only at high COBF concentrations the rate is reduced considerably in accordance with what is generally observed in CCTP. ${ }^{c, d}$ It was also observed that at lower COBF loadings $M_{\mathrm{w}}$ increases (with a corresponding broadening of the distribution) at higher conversions. This is thought to be a result of the presence of the impurities in dioxane. Dioxane contains a very small percentage of peroxides (due to decomposition of dioxane) and these peroxides have a marked effect on the catalytic activity of COBF and will obviously have a greater effect when using lower amounts of COBF. ${ }^{6-d}$ To confirm this conclusion we measured the chain transfer constants of COBF in MMA polymerization in distilled and undistilled dioxane and found $C_{\mathrm{T}}$ values of around $44 \times 10^{3}$ and $9 \times 10^{3}$. We therefore decided to measure more exact values for $C_{\mathrm{T}}$ in distilled dioxane (vide infra) (Figure S1, Supporting Information).

We also investigated the effect of replacing a fraction of $S$ by AMS on the kinetics and molar mass evolution, as it is known that AMS affects the rate of reaction and molar mass when copolymerised with $\mathrm{S}$ in the presence of $\mathrm{COBF}^{8,16} \mathrm{By}$ replacing $S$ with AMS (from 0 to $10 \%$ ) in a SMA copolymerization, while maintaining a constant molar ratio between MAh and the styrenic monomers (S+AMS), a similar trend in behavior is seen. An increase in the amount of AMS added decreases the molar mass (which remains virtually constant with conversion) and decreases the polymerization rate (see Figure 2). 

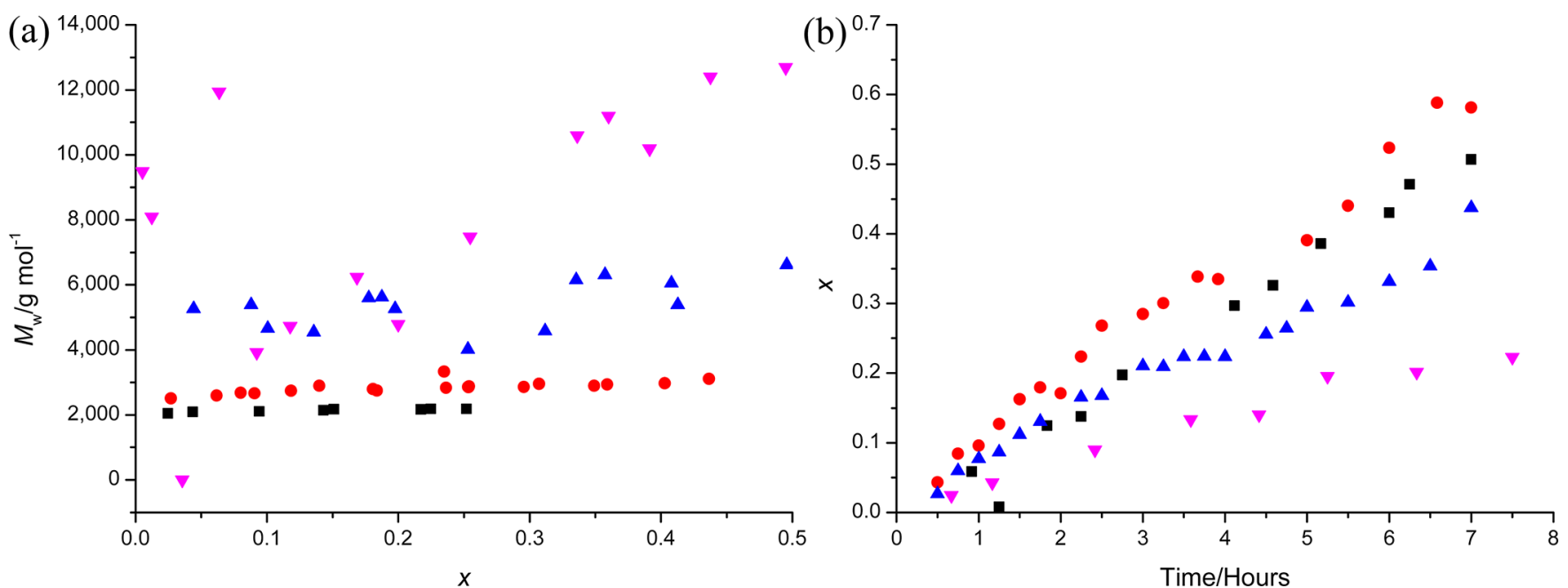

Figure 2. The effect of AMS/S ratio on (a) molar mass evolutions and (b) conversion vs time plots for the COBF-mediated free-radical polymerization of S/AMS/MAh (S+AMS: MAh $=50: 50)$ at $60{ }^{\circ} \mathrm{C}$ in undistilled dioxane. $[\mathrm{COBF}]=23 \mathrm{ppm} . \mathrm{S}: \mathrm{AMS}=0: 50(\boldsymbol{\square}), 45: 5(\mathrm{red} \boldsymbol{\bullet}), 48: 2$ (blue $\boldsymbol{\Delta})$, 50:0 (pink $\boldsymbol{\nabla})$.

In conclusion, it is clear from these results that CCTP leads to efficient molar mass control in the copolymerization of SMA and that, in line with previous results, ${ }^{8}$ replacing a fraction of $S$ by AMS leads to a more efficient CCTP process.

End Group Determination. In the previous section, we showed that CCTP indeed leads to efficient molar mass control, but we still need to establish the polymer microstructure and end groups in these polymerizations. Since an almost perfectly alternating copolymer can be easily synthesized under conventional free radical conditions by using a 50:50 ratio of styrenic monomers to maleic anhydride, we expected the polymerization of $S$ and MAh under CCTP conditions to also result in an (almost perfectly) alternating copolymer. From the MALDI-ToF-MS spectrum in Figure 3a, which shows a repeat unit of $202 \mathrm{Da}$ (SMA), it is clear that this is indeed the case. Distributions corresponding to $\mathrm{p}(\mathrm{SMA})_{n}$ with $1,2,3$, and 4 extra $S$ units, $\mathrm{p}(\mathrm{SMA})_{n}(\mathrm{~S})_{1-4}$, can be observed. Besides the potential occurrence of preferential initiation and transfer reactions, these additional $S$ units originate from the fact that although MAh cannot homopolymerise, $S$ can and thus it is possible that within the polymer chain there are two $S$ units next to one another. This trend is shown further in Figure $3 \mathrm{~b}$, which shows an alternating topology in the fingerprint of the MALDI-ToF-MS contour plot. A slight deviation from a perfectly alternating topology is also evident, with a higher amount, on average, of $S$ units versus MAh units in the polymer chain.

Although there are more styrene units than maleic anhydride units in the copolymer, close inspection of a ${ }^{1} \mathrm{H}-{ }^{13} \mathrm{C}$ gHMQC NMR spectrum (Figure 4) indicates that maleic anhydride predominantly forms the end group. Figure 4 shows the crosspeak corresponding to the $=\mathrm{CH}$ of an unsaturated MAh moiety at $6.5\left({ }^{1} \mathrm{H}\right)$ and $135\left({ }^{13} \mathrm{C}\right) \mathrm{ppm}$. For an internal styrenic double bond, a cross peak at around $5.5\left({ }^{1} \mathrm{H}\right)$ and $114\left({ }^{13} \mathrm{C}\right) \mathrm{ppm}$ would be expected, and which is not observed here.

The result that predominantly polymers are formed with an unsaturated MAh-group is very interesting and was, at first, very surprising for two reasons. First of all, under the used reaction conditions, the fraction of propagating MAh radicals is less than about $10 \%$ of the overall propagating radical population, ${ }^{2}$ implying that $C_{\mathrm{T}, \mathrm{MAh} \text {-radicals }} \gg 10 \times C_{\mathrm{T}, \mathrm{S} \text {-radicals. Second, at first }}$

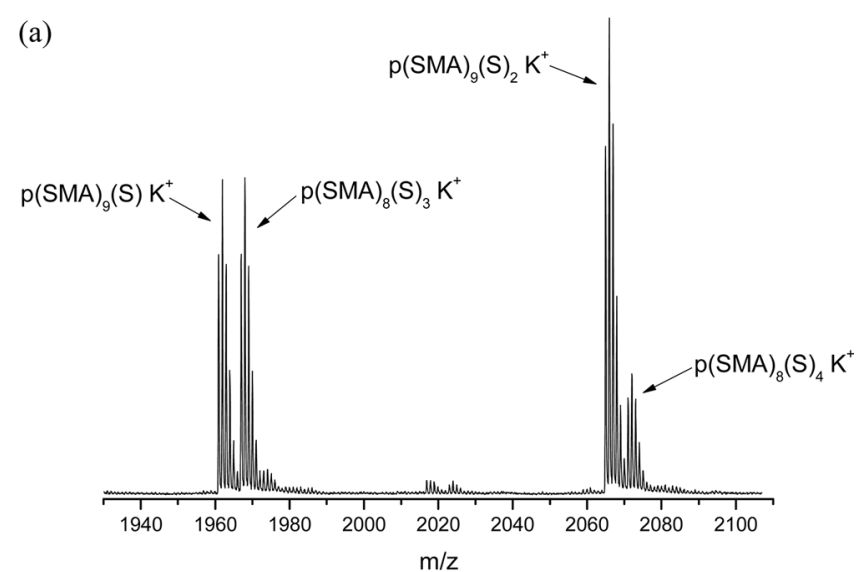

(b)

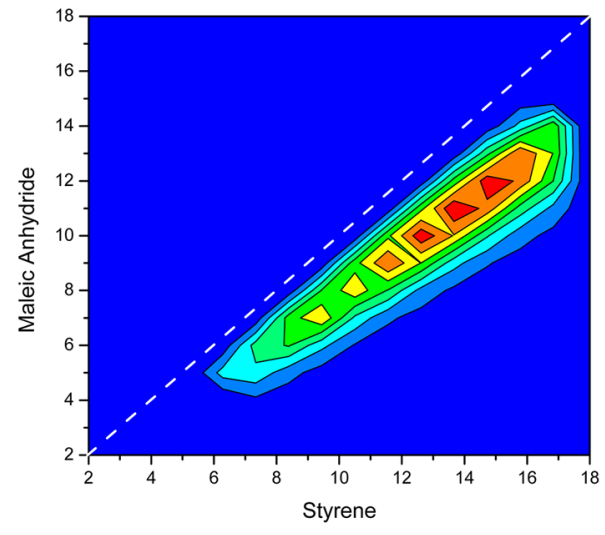

Figure 3. MALDI-ToF-MS (THF, $\mathrm{K}^{+}$salt) (a) spectrum and (b) contour plot of pSMA.

glance, the MAh-radical seems to be similar to an acrylate radical, for which $C_{\mathrm{T}}$ is low. Where this radical differs from an acrylate radical, however, is the nature of the $\beta$-hydrogen atom that is abstracted. Whereas in an acrylate it is abstracted from a secondary carbon atom, in MAh it is abstracted from a tertiary carbon; in fact, it is a similar carbon as those which lead to the so-called midchain radicals in acrylate polymerization which originate from chain transfer to polymer. ${ }^{17}$ Hence, in retrospect, the abstracted hydrogen atom may actually be 


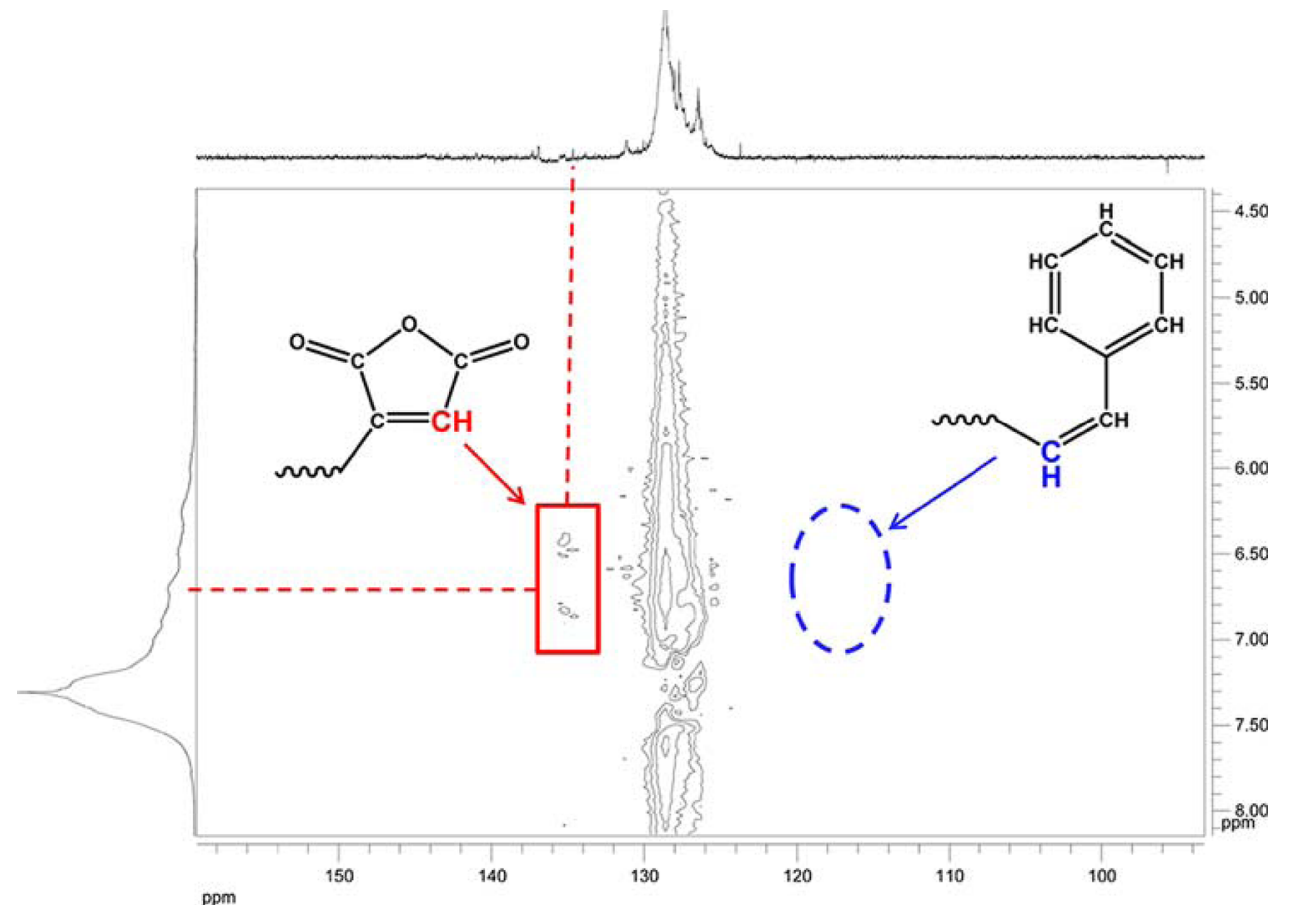

Figure 4. Partial ${ }^{1} \mathrm{H}-{ }^{13} \mathrm{C}$ gHMQC NMR (acetone- $d_{6}$ ) spectrum of pSMA.

quite labile and this conclusion is supported by high-level quantum chemical calculations as discussed in the following section (vide infra).

The addition of AMS to the copolymerization of $S$ and MAh was thought to not only improve the control over the molar mass but also produce polymers with an AMS end group with an external double bond. MALDI-ToF-MS data again indicate that an almost perfectly alternating copolymer of SMA has been synthesized, as evidenced by the repeating unit of $202 \mathrm{Da}, \mathrm{p}(\mathrm{SMA})$ (Figure 5a). Several distributions can be observed. As with $S$ and MAh polymerized without AMS, polymers with a range of units of MAh and $S$ are observed, $\mathrm{p}(\mathrm{SMA})_{n}(\mathrm{~S})_{x}$ (the labels for distributions where $x>2$ have been omitted from Figure 5a for clarity). In addition to these distributions, a range of AMS units per $\mathrm{p}(\mathrm{SMA})_{\mathrm{n}}(\mathrm{S})_{x}$ chain can also be seen, $\mathrm{p}(\mathrm{SMA})_{n}(\mathrm{~S})_{x}(\mathrm{AMS})_{0-6}$. Clearly, in these cases, more than one AMS has been copolymerised with $S$ and MAh into the polymer chain. This is further confirmed by the MALDI-ToF-MS contour plot (Figure 5b), which shows a distribution of AMS units for a range of SMA units. For simplicity's sake, we denote all SMA polymers containing AMS as PASMA in the remainder of this paper.

In order to establish whether at least one of the AMS units was situated at the end of the polymer forming the end group, ${ }^{1} \mathrm{H}-{ }^{13} \mathrm{C}$ gHMQC NMR was again used. The cross-peak at 5.5 $\left({ }^{1} \mathrm{H}\right)$ and $116\left({ }^{13} \mathrm{C}\right) \mathrm{ppm}$ (Figure 6) indicates the presence of $a$ $=\mathrm{CH}_{2}$ corresponding to an external double bond of an AMS unit. According to ${ }^{1} \mathrm{H}$ NMR, the ratio of $=\mathrm{CH}_{2}$ (AMS) to aromatic protons was found to be 1:5, which assuming almost equal ratio of $S$ and MAh per chain and only one AMS unit gives a number-average molar mass of $1100 \mathrm{~g} / \mathrm{mol}$. This is comparable to the value obtained using SEC of $900 \mathrm{~g} / \mathrm{mol}$ (adjusted using Mark-Houwink parameters), indicating that most chains contain an AMS end group with an unsaturated external double bond.

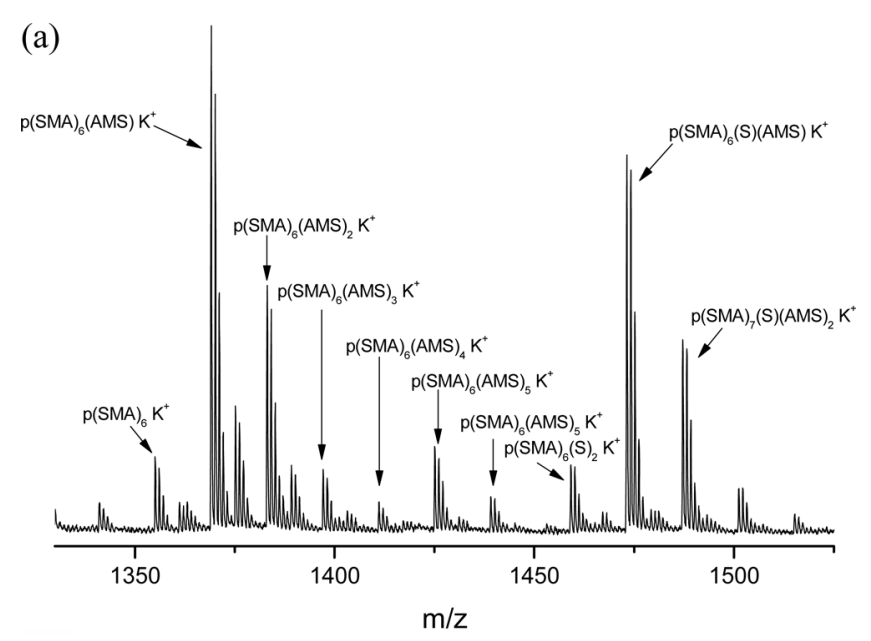

(b)

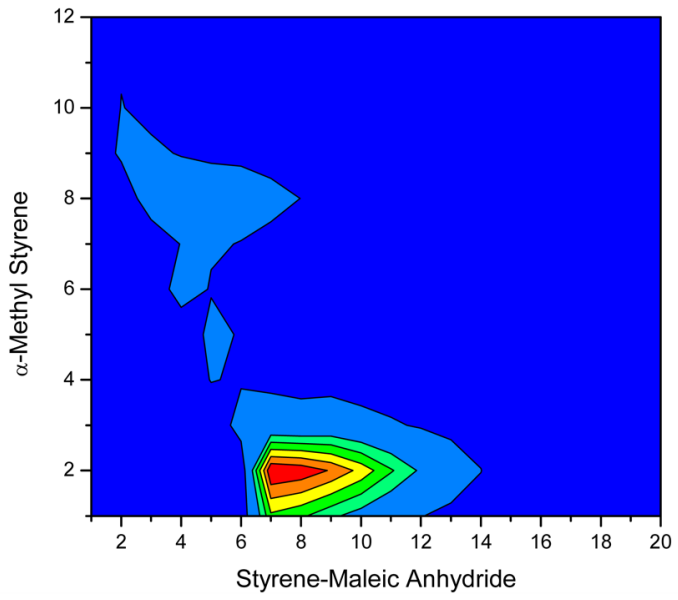

Figure 5. MALDI-ToF-MS (THF, $\mathrm{K}^{+}$salt) (a) spectrum and (b) contour plot of pASMA. 


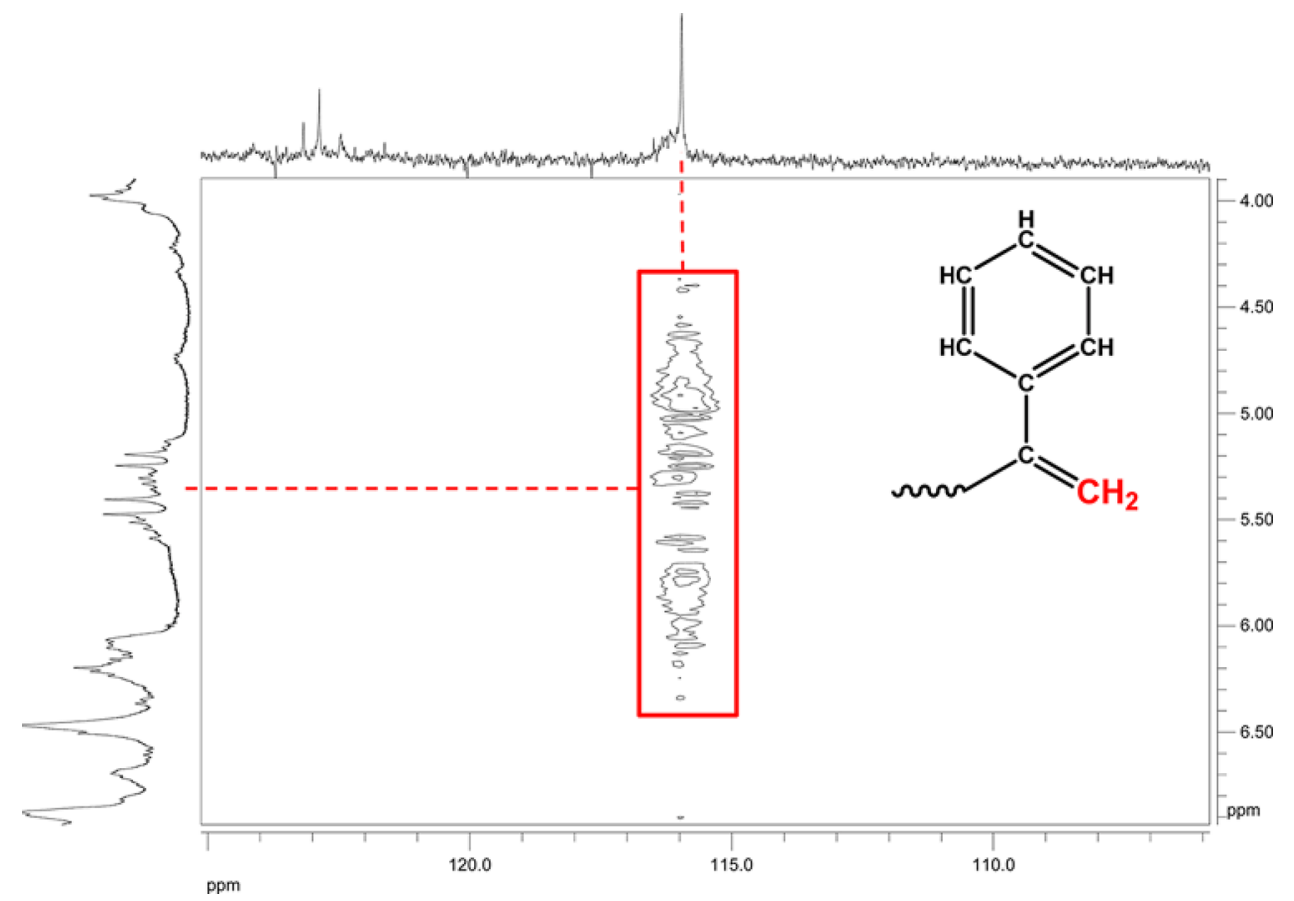

Figure 6. Partial ${ }^{1} \mathrm{H}-{ }^{13} \mathrm{C}$ gHMQC NMR (acetone- $d_{6}$ ) spectrum of pASMA (entry 1, Table 1).

\section{Scheme 1. Structures of pSMA and pASMA}

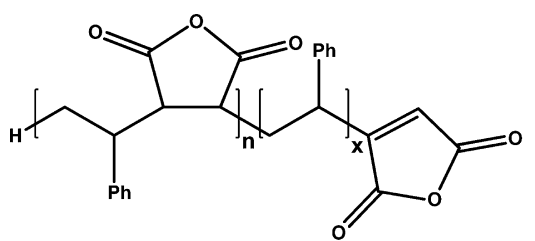

pSMA

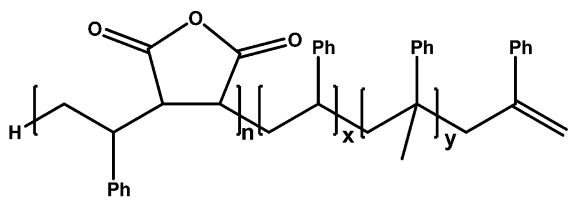

pASMA
In conclusion, CCTP can be used to synthesize both S-MAh and S-MAh-AMS copolymers, in which the end groups have been determined to be an unsaturated MAh and an unsaturated AMS moiety, respectively (Scheme 1).

Computational Studies. As stated in the previous section, we were surprised to find that the predominant end group in pSMA was MAh and that the only obvious explanation for this finding would be a very labile hydrogen atom in the MAh radical. In order to confirm this explanation, we performed a computational study on two model reactions as shown in Scheme 2. In this study, we only considered the reaction thermodynamics, rather than the kinetics, because those calculations would currently be computationally too expensive. Additionally, we would need to resort to computational methods that have not been tested sufficiently for this type of reactions to really draw conclusions with chemical accuracy. Having said this, we feel that for the current purposes just considering the overall energy is sufficient as the EvansPolanyi rule often applies when considering very similar reactions, i.e., that the more exothermic the reaction, the lower the barrier. ${ }^{18}$ Furthermore, since we are only interested in the differences between the exothermicity of the reactions of the two radicals we used methyl radical as the other reacting radical. This is obviously an arbitrary choice, but since it is the same reagent in both reactions, it will only affect the absolute values of the thermodynamic parameters, but not the differences. The final results of these calculations are
Scheme 2. Model Reactions and Associated Free Energy Changes (298.15K, kJ mol ${ }^{-1}$ ) for the Hydrogen Abstraction Reactions in the CCTP of SMA

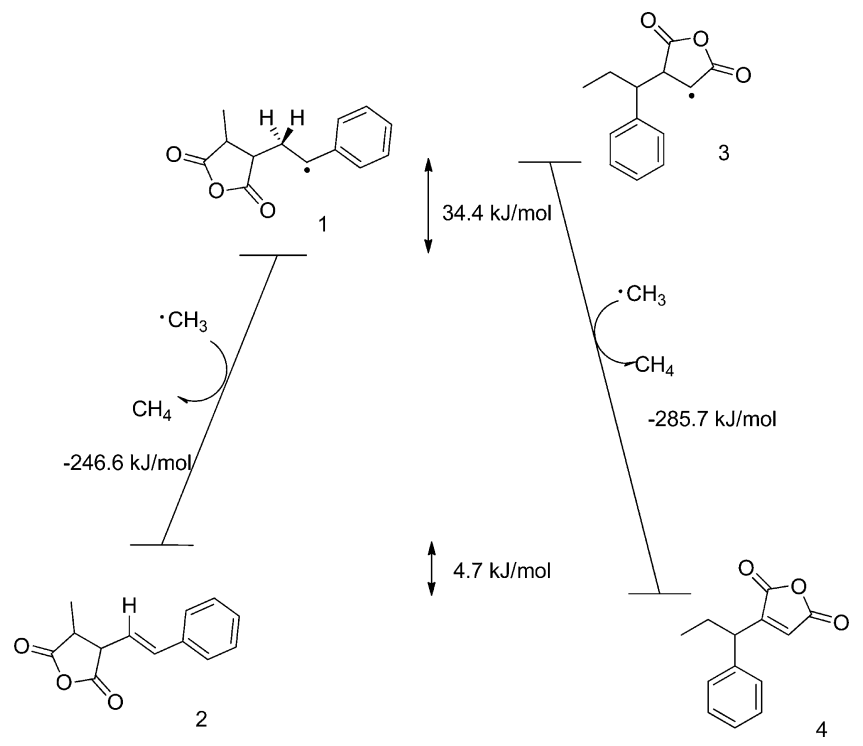

summarized in Table 1; further details are available in the Supporting Information. 
Table 1. Summary of the Calculated Reaction Thermodynamics of the Two Model Systems ${ }^{a}$

$\begin{array}{lccc} & \begin{array}{c}\Delta S \\ \left(\mathrm{~J} \cdot \mathrm{mol}^{-1} \cdot \mathrm{K}^{-1}\right)\end{array} & \begin{array}{c}\Delta H \\ \left(\mathrm{~kJ} \cdot \mathrm{mol}^{-1}\right)\end{array} & \begin{array}{c}\Delta G \\ \left(\mathrm{~kJ} \cdot \mathrm{mol}^{-1}\right)\end{array} \\ \mathbf{1}+\mathrm{CH}_{3} \cdot \rightarrow \mathbf{2}+\mathrm{CH}_{4} & -14.53 & -251.0 & -246.6 \\ \mathbf{3}+\mathrm{CH}_{3} \rightarrow \mathbf{4}+\mathrm{CH}_{4} & -20.79 & -291.9 & -285.7\end{array}$

${ }^{a}$ Gas phase reaction entropies $(\Delta S)$, enthalpies $(\Delta H)$, and Gibbs free energies $(\Delta G)$ calculated at $298.15 \mathrm{~K}$ at the G3(MP2)-RAD//B3LYP/6-31G(d) level of theory using the rigid rotor/harmonic oscillator approximation.

The results in Table 1 clearly show that the second reaction, i.e., the reaction modeling the hydrogen transfer from a MAh radical, is about $40 \mathrm{~kJ} \cdot \mathrm{mol}^{-1}$ more exothermic. It is interesting to note that the product from the second reaction (4) is very similar in stability to the product of the first reaction (2), only $4.7 \mathrm{~kJ} / \mathrm{mol}$ lower, but the reactant 3 is higher in energy. Obviously both reactions here are highly exothermic because the abstracting radical is $\mathrm{CH}_{3}{ }^{\circ}$, and it is likely that with the catalyst the reaction is a lot less exothermic. This does not, however, affect the large difference of $40 \mathrm{~kJ} \cdot \mathrm{mol}^{-1}$ in reaction energies, which is indeed in line with the experimentally observed end groups.

Determination of Chain Transfer Constant of COBF for SMA Copolymers. In order to determine the chain transfer constant $\left(C_{\mathrm{T}}\right)$ of COBF in S-AMS-MAh copolymerizations, polymerizations to low conversion $(<5 \%)$ were carried out in freshly distilled 1,4-dioxane (to reduce deactivation of the catalyst due to the presence of peroxides) at various COBF concentrations and for four different S:AMS ratios.

The easiest and most widely used method of determining the chain transfer constant $\left(C_{\mathrm{T}}\right)$ of COBF is the Mayo method. By determining the $M_{\mathrm{n}}$ or $M_{\mathrm{w}}$ from SEC data, the degree of polymerization can be calculated, which is then plotted as $1 /$ $D P_{\mathrm{n}}$ or $2 / D P_{\mathrm{w}}$ against the ratio of chain transfer agent concentration to monomer concentration. The slope of this line is the $C_{\mathrm{T}}$, in accordance with eq 1 .

$$
\frac{1}{D P_{\mathrm{n}}}=(1+\lambda) \frac{\left\langle k_{\mathrm{t}}\right\rangle[\mathrm{R} \cdot]}{k_{\mathrm{p}}[\mathrm{M}]}+C_{\mathrm{M}}+C_{\mathrm{T}} \frac{[\mathrm{Co}]}{[\mathrm{M}]}
$$

In this equation, $\lambda$ is the fraction of radicals undergoing termination by disproportionation, $\left\langle k_{\mathrm{t}}\right\rangle$ the chain length averaged termination rate coefficient, $\left[\mathrm{R}^{\circ}\right]$ the overall radical concentration, $[\mathrm{M}]$ the monomer concentration, $C_{M}$ the chain transfer to monomer constant, [Co] the active catalyst concentration and $C_{\mathrm{T}}$ the chain transfer constant (defined as $k_{\mathrm{tr}} / k_{\mathrm{p}}$, where $k_{\mathrm{tr}}$ is the chain transfer rate coefficient and $k_{\mathrm{p}}$ the propagation rate coefficient). Although using $M_{n}$ to determine the degree of polymerization is theoretically the most accurate way, $M_{\mathrm{w}}$ is often used (as $M_{\mathrm{w}} / 2 m_{0}$ ) as it is a more robust experimental parameter, particularly for low molar mass polymers. It should also be noted that a dispersity $(\boxplus)$ of 2 is assumed, a value which is commonly found in chain transferdominated polymerizations. ${ }^{19}$

The Mayo method has one major disadvantage. When dealing with low molar mass polymers, it is often difficult to separate the polymer from the solvent peak in SEC. This means that obtaining an accurate baseline is not always possible, and thus the average molar mass, particularly $M_{n}$, is less reliable giving an unrealistic $C_{\mathrm{T}}$ value. This issue has previously been discussed in detail and a comparison made between $C_{\mathrm{T}}$ values determined using the Mayo method $\left(M_{\mathrm{n}}\right.$ and $M_{\mathrm{w}}$ from SEC measurements) and the chain length distribution (CLD) method. ${ }^{19 a, 20}$ The CLD method uses the slope, $\Lambda$, of the chain length distribution $\mathrm{P}(M)$, plotted as $\ln (\mathrm{P}(M))$, vs $M$ to determine the chain transfer constant. ${ }^{21} \Lambda$ taken in the higher molar mass region, $\Lambda_{\mathrm{H}}$ is theoretically the most accurate, in accordance with eq 2 .

$$
\begin{aligned}
& \lim _{M \rightarrow \infty} \frac{\mathrm{d}(\ln P(M))}{\mathrm{d} M} \\
& =-\left(\frac{\left\langle k_{\mathrm{t}}\right\rangle\left[\mathrm{R}^{\bullet}\right]}{k_{\mathrm{p}}[\mathrm{M}]}+C_{\mathrm{M}}+C_{\mathrm{T}} \frac{[\mathrm{Co}]}{[\mathrm{M}]}\right) m_{0}^{-1} \\
& =\Lambda_{\mathrm{H}}
\end{aligned}
$$

However, more reliable results are often obtained when the slope of the distribution is taken at the molar mass of the peak of the original chromatogram, $\Lambda_{\mathrm{p}} \cdot{ }^{19 \mathrm{a}, 20}$ Now plotting $\Lambda_{\mathrm{p}} m_{0}$ against $[\mathrm{COBF}] /[\mathrm{M}]$ gives a plot similar to the conventional Mayo plot with a slope equal to $C_{\mathrm{T}}$.

In this paper we used both the Mayo method based on $M_{\mathrm{w}}$ and the CLD method for determining the chain transfer constants. The obtained Mayo plots for the four different S:AMS ratios are shown in Figure 7 (we refer to the Supporting

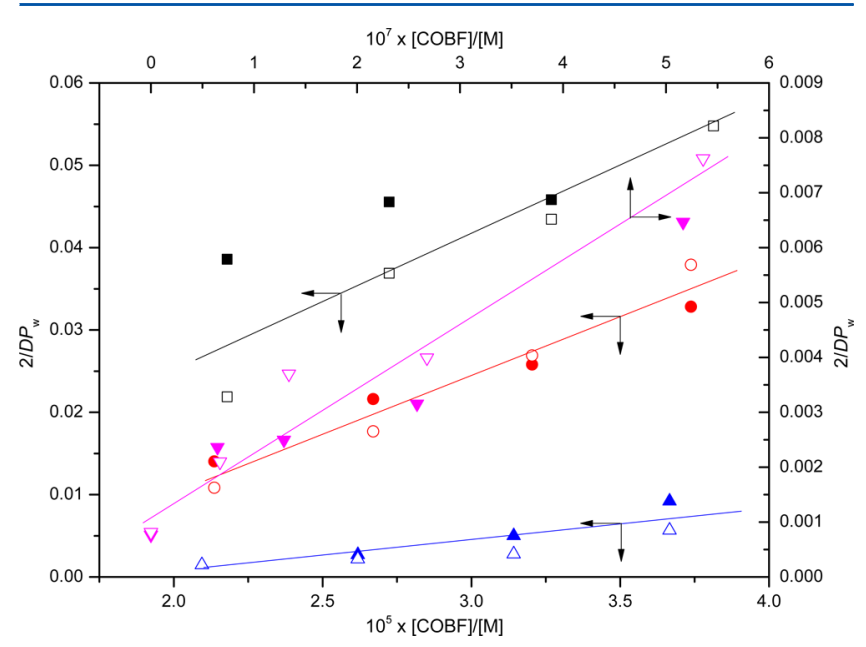

Figure 7. Mayo plots for the determination of the determination of the chain transfer constant of COBF in S, MAh and AMS in dioxane at 60 ${ }^{\circ} \mathrm{C}$. Molar ratios of $\mathrm{S}$ to AMS = 45:5 (black), 48:2 (red), 50:0 (blue), and 0:50 (magenta). Ratio of $S+A M S$ to MAh $=1: 1$. Closed symbols $=$ repeat 1 ; open symbols $=$ repeat 2 .

Information for the corresponding molar mass distributions, In $P(M)$ and CLD plots) and the results for the chain transfer constants are summarized in Table 2 .

First of all it can be seen that there is a good agreement between the two methods and that with increasing AMS content the chain transfer constant increases (as expected). What is interesting to note is that, by CCTP standards, the chain transfer constants are moderately low. Especially when comparing the value obtained for the 50\% AMS/50\% MAh system $\left(\sim 10^{4}\right)$ with that for pure AMS $\left(\sim 10^{5}\right)$ then it is an order of magnitude lower. It is, however, not surprising when one considers the fact that these chain transfer constants are ratios of the average $k_{\mathrm{tr}}$ and the average $k_{\mathrm{p}}$, and in the case of (A)SMA polymerization, the average $k_{\mathrm{p}}$ is quite high ${ }^{2}$ (and much higher than the $k_{\mathrm{p}}$ for pure AMS! $)^{8 \mathrm{~b}}$ For a monomer feed fraction $f_{\text {MAh }}=0.5$ in a SMA copolymerization $k_{\mathrm{p}}>2000$ 
Table 2. Chain Transfer Constants $\left(C_{\mathrm{T}}\right)$ in the COBFMediated Free Radical Polymerization of S-MAh:AMS at $60^{\circ} \mathrm{C}$ in Freshly Distilled Dioxane

$\begin{array}{ccc}\text { S:AMS }^{a} & \text { Mayo method } & \\ 50: c & \text { CLD method }^{c, d} \\ 48: 2 & (0.4 \pm 0.1) \times 10^{3} & (0.5 \pm 0.1) \times 10^{3} \\ 45: 5 & (1.4 \pm 0.3) \times 10^{3} & (1.4 \pm 0.4) \times 10^{3} \\ 0: 50 & (1.8 \pm 0.3) \times 10^{3} & (1.6 \pm 0.4) \times 10^{3} \\ & (11.0 \pm 0.9) \times 10^{3} & (11.9 \pm 0.7) \times 10^{3}\end{array}$

${ }^{a}$ Molar ratios. Ratio of AMS and $S$ to MAh $=1: 1 .{ }^{b}$ Mayo method based on eq 1 using $D P_{\mathrm{n}}=M_{\mathrm{w}} /\left(2 \cdot m_{0}\right)$. ${ }^{c}$ Average value determined by plotting all points in a single graph and determining the slope of a best fit line. ${ }^{d}$ CLD method based on eq 2 using $\Lambda_{\mathrm{P}}$ instead of $\Lambda_{\mathrm{H}}$.

$\mathrm{dm}^{3} \cdot \mathrm{mol}^{-1} \cdot \mathrm{s}^{-1}$, which implies that $k_{\mathrm{tr}}>10^{6} \mathrm{dm}^{3} \cdot \mathrm{mol}^{-1} \cdot \mathrm{s}^{-1}$ in the $50 \% \mathrm{~S} / 50 \%$ MAh copolymerization system and $k_{\mathrm{tr}}>10^{7}$ $\mathrm{dm}^{3} \cdot \mathrm{mol}^{-1} \cdot \mathrm{s}^{-1}$ in the $50 \%$ AMS/50\% MAh copolymerization system (assuming that $k_{\mathrm{p}}$ is of the same order of magnitude as that in SMA). Both values are about an order of magnitude larger than what is observed in an ordinary CCTP of styrene and in AMS, respectively. This observation suggests that there may be a strong penultimate unit effect on the transfer reaction in this system, but there are too many uncertainties in the rate parameters used to draw any firm conclusions. What seems to be a clear conclusion, however, is that the $k_{\text {tr }}$ of MAh-radical to COBF is very high; in fact we expect it to be larger $10^{7}$ $\mathrm{dm}^{3} \cdot \mathrm{mol}^{-1} \cdot \mathrm{s}^{-1}$ (we used here the experimental result that only MAh end groups are observed and the kinetic estimate that only about $10 \%$ of the propagating radical population contains a MAh terminal unit). This is in line with the results from the quantum-chemical calculations.

Post-Polymerization Reactions of pSMA. The CCTPderived PSMA macromonomers have a predominantly maleic anhydride end group, which contains a vinylic functionality, making the polymer ripe for a variety of post-polymerization modifications. CCTP has been combined with post-polymerization reactions, such as thiol-ene chemistry, frequently in the past few years. ${ }^{22}$ However, to our knowledge CCTP has never been combined with a Diels-Alder cycloaddition. In the following section, we describe proof of principle reactions to modify pSMA polymers (obtained using CCTP) via both thiol-ene and Diels-Alder cycloaddition reactions (Scheme 3).

Diels-Alder Reactions. Diels-Alder reactions require a diene and a dieneophile, usually a single double bond. ${ }^{23}$ Although maleic anhydride reacts readily with a range of dienes, the substitution of a proton with an electron donating group such as the methyl in citraconic anhydride or in fact the polymer chain in pSMA, significantly decreases the reactivity of the dienophile. ${ }^{24}$ Danishefsky's diene is known to be one of the most electron-rich dienes and therefore one of the most effective for electron-deficient dieneophiles. ${ }^{25}$ Addition of this diene (in excess) to pSMA at elevated temperatures resulted in a successful Diels-Alder reaction (pSMADD), as illustrated by the MALDI-ToF-MS spectrum (Figure 8), which shows the successful addition of Danishefsky's diene (DD) to pSMA. The use of ${ }^{1} \mathrm{H}$ NMR as an analytical tool is problematic due to the broad signals observed.

Thiol-Ene Reactions. The addition of a simple alkyl thiol to pSMA in the presence of DMPP as a catalyst should result in the Michael addition of these two species. Thiol-ene chemistry can be carried out on the vinylic functionality of MAh-type end groups, as evidenced by model reactions using citraconic anhydride and dodecanethiol which indicated that the thiol had reacted exclusively with the double bond and not with the anhydride ring (Figure S10, Supporting Information).

An excess of octanethiol was reacted with pSMA in the presence of DMPP to produce the Michael addition product, as confirmed via MALDI-ToF-MS (Figure 9). Because of the sheer number of peaks it was difficult to identify whether certain peaks corresponded to unreacted starting material or the reaction product. In addition the degree of conversion could not be quantified due to the intrinsic nature of MALDIToF-MS and the fact that it is the only suitable analytical method. However, the spectrum is significantly different

Scheme 3. Attempted Post-Polymerization Functionalizations of pSMA

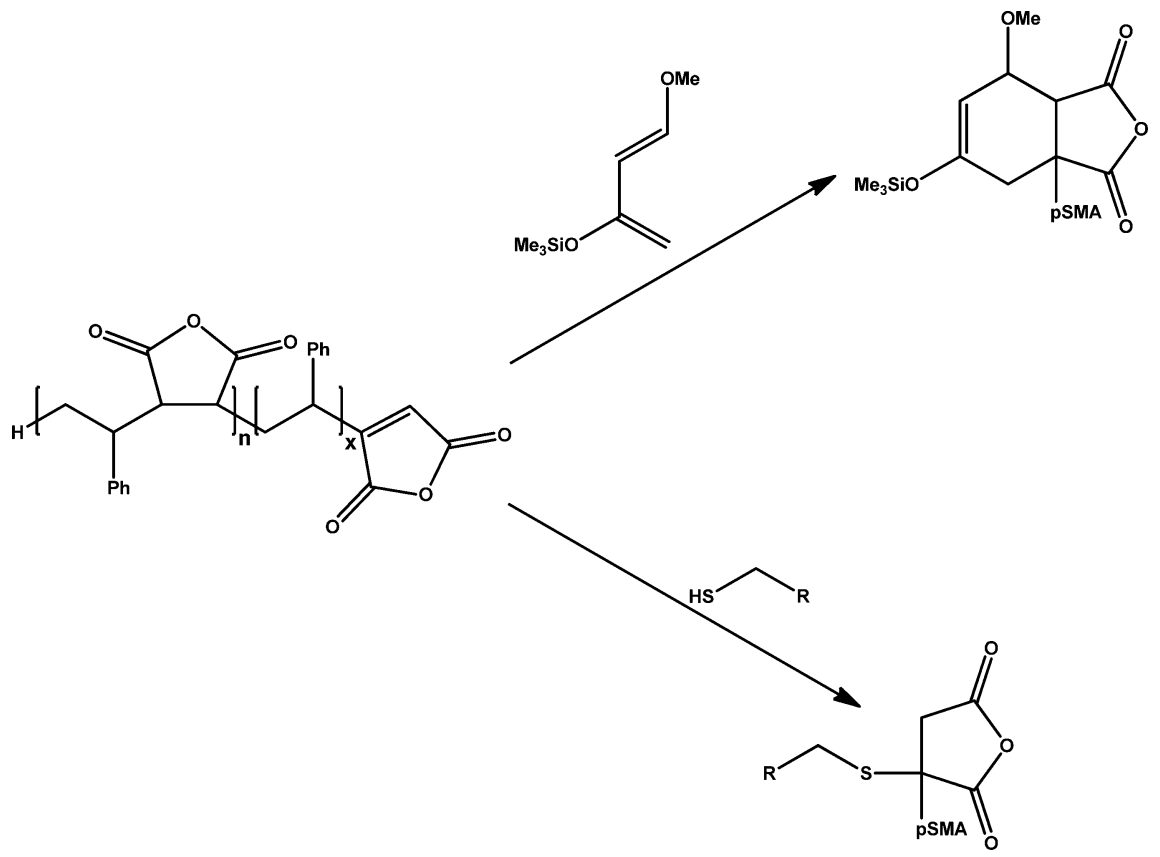



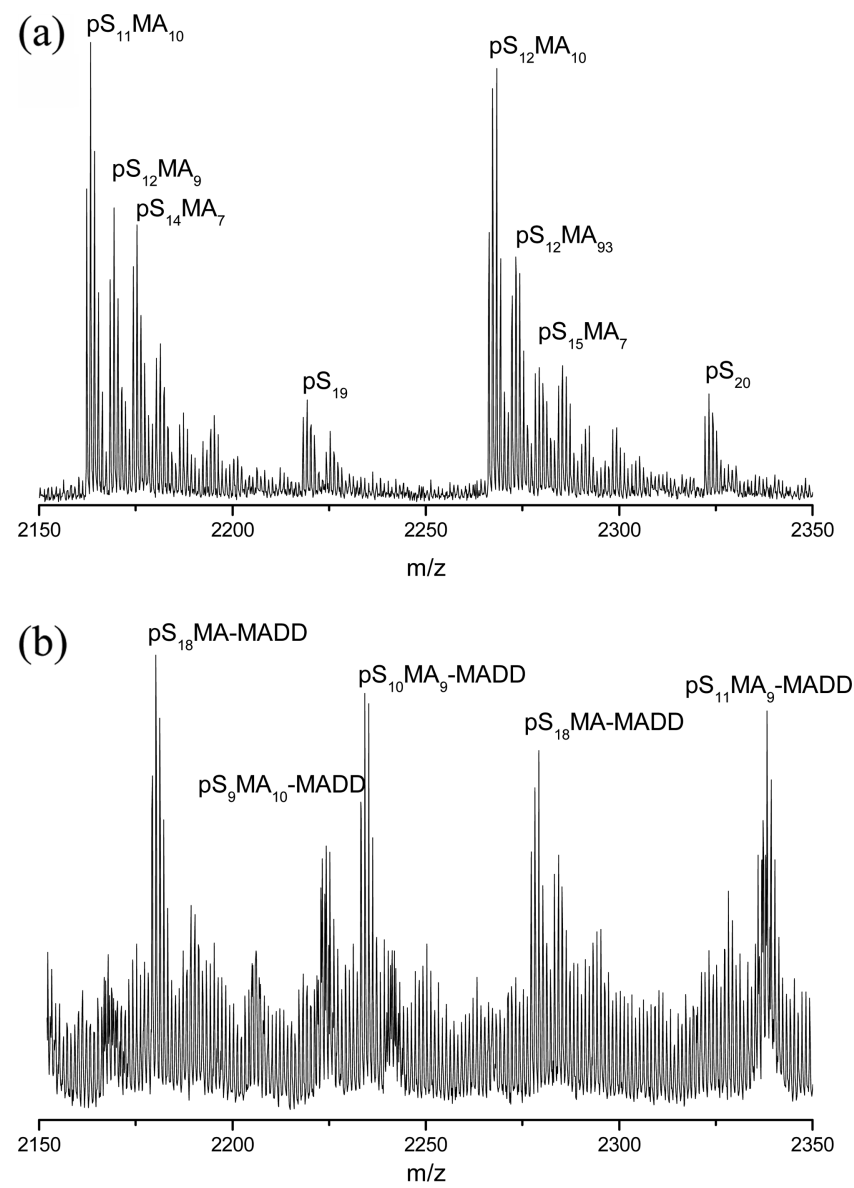

Figure 8. MALDI-ToF-MS spectrum of (a) pSMA and (b) pSMA after reaction with Danishefsky's diene (DD).
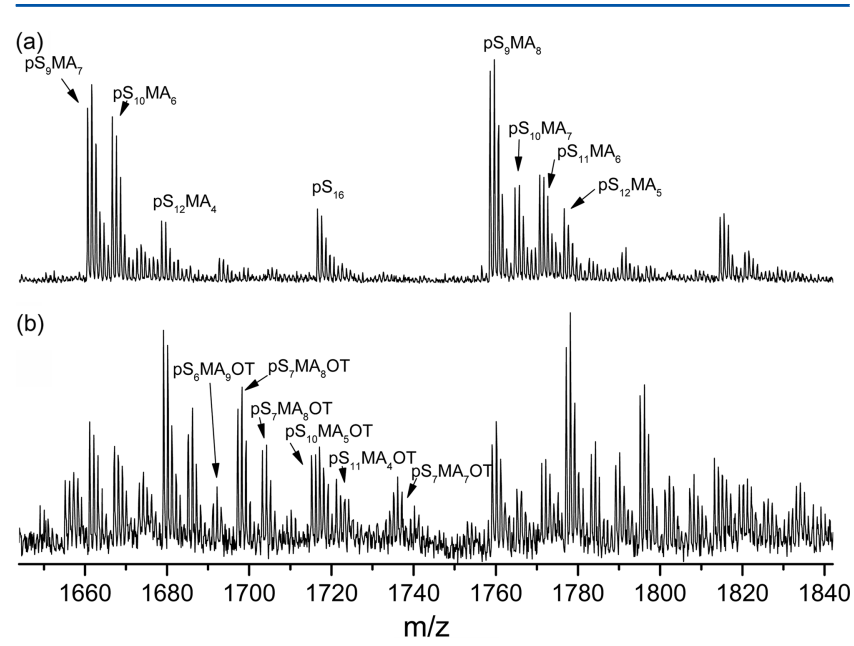

Figure 9. MALDI-ToF-MS spectrum of (a) pSMA and (b) pSMA after reaction with octanethiol (OT).

compared to the starting macromonomer demonstrating that a successful coupling reaction has taken place.

Copolymerization Behavior. Macromonomers made via CCTP have been shown to undergo two different reactions when in the presence of an additional (methacrylic, acrylic or styrenic) monomer under free-radical conditions: additionfragmentation chain transfer (AFCT) and graft copolymerization. ${ }^{6 c, d}$ The tendency of a macromonomer to undergo either AFCT or graft copolymerization is dependent on the nature of the penultimate monomer unit of the macromonomer (i.e., the monomer unit next to the unsaturated monomer end group) and the nature of the secondary monomer. ${ }^{26}$

Accordingly, we expect pSMA, where the penultimate unit is most likely to be a styrene unit, and pASMA, where the penultimate unit is most likely a MAh or $S$ unit, both to undergo predominantly graft copolymerization with either styrene or an acrylate.

The copolymerization of pSMA with 35 equiv of styrene results in a clear increase in molar mass (Figure 10), and no

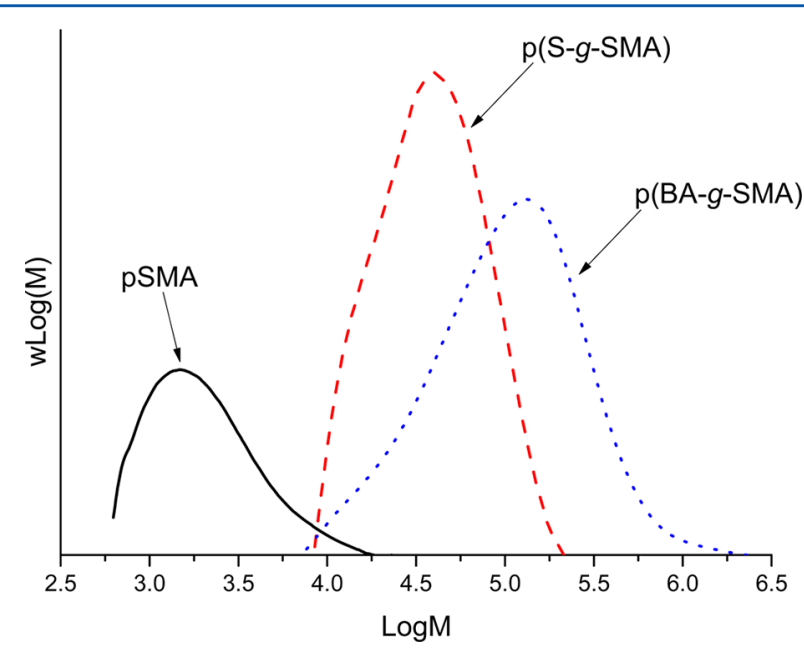

Figure 10. Molar mass distribution of pSMA p(S-g-SMA) and p(BA- $b$ SMA). Measured against PS standards in THF. Corrected for conversion.

residual macromonomer is observed. This indicates that a graft copolymer of $\mathrm{p}$ (S-g-SMA) has been obtained. A slightly low molar mass shoulder can be observed in the molar mass distribution, which could be due to the formation of polystyrene. The copolymerization of pSMA with butyl acrylate (BA) exhibits similar behavior, and $\mathrm{p}(\mathrm{BA}-\mathrm{g}-\mathrm{SMA})$ is clearly formed (Figure 10).

PASMA, on the other hand, does not react so readily with styrene and butyl acrylate and a large amount of macromonomer remains unreacted after completion of the reaction (Figure 11). This may simply be due to a slower copolymerization as the radical that is formed upon addition to the macromonomer can be stabilized by delocalization of the electron in the phenyl ring, ${ }^{26}$ but more extensive copolymerization studies, beyond the scope of the current work, would be required to establish this.

Although the reason behind the lower reactivity of the pASMA system has not been completely clarified, it is interesting to note the obvious difference in reactivity between pSMA and pASMA and that the system with the most efficient CCTP yields the least reactive macromonomer for further polymerization.

\section{CONCLUSIONS}

In this work, we have demonstrated that low molar mass, endfunctional polymers of styrene and maleic anhydride can be efficiently synthesized via CCTP and that replacing part of the styrene with $\alpha$-methylstyrene makes the process even more efficient. The polymers prepared without $\alpha$-methylstyrene are characterized by a reactive unsaturated maleic anhydride end group that can be postfunctionalized by Diels-Alder and 


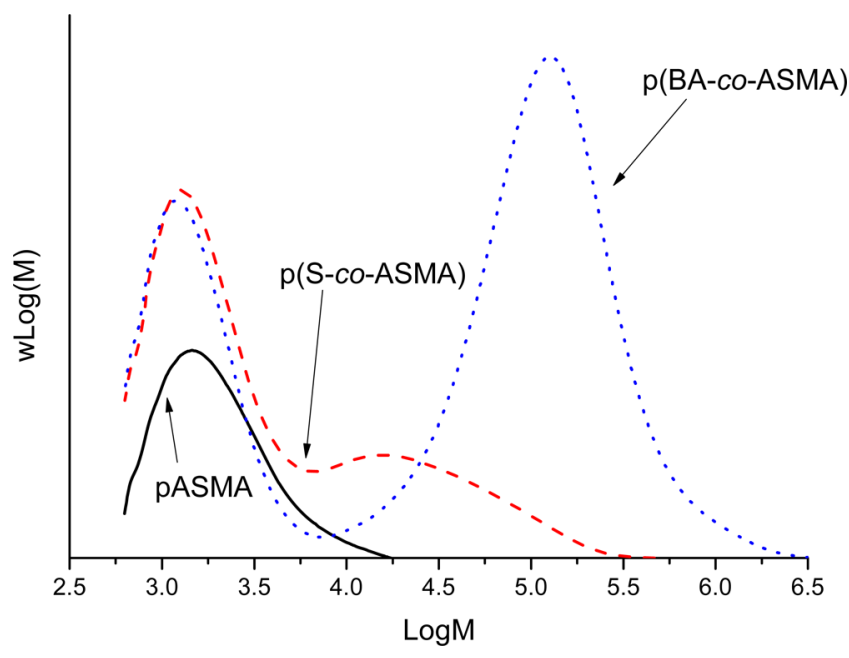

Figure 11. Molar mass distribution of pASMA $p(S-g-A S M A)$ and $\mathrm{p}$ (BA-b-ASMA). Measured against PS standards in THF. Corrected for conversion.

thiol-ene reactions. These polymers are also efficient comonomers in copolymerizations with styrene and butyl acrylate. The polymers prepared with $\alpha$-methylstyrene are characterized by an unsaturated $\alpha$-methylstyrene end group, which showed a much lower reactivity in further copolymerization reactions. Hence, if only low-molar mass SMA copolymers are required, it is worthwhile considering the addition of a small amount of $\alpha$-methylstyrene, which makes the CСTP process more efficient and necessitates a lower amount of catalyst. However, if the macromonomers are to be used as comonomers or need to be end-functionalized, then it is probably better to use just styrene and maleic anhydride.

\section{ASSOCIATED CONTENT}

\section{S Supporting Information}

Details of quantum calculations, additional $C_{\mathrm{T}}$ values for MMA in bulk and distilled/undistilled dioxane, molar mass distributions of $\ln P(M)$ vs $M$ plots for pSMA and pASMA copolymers, summary of chain transfer constants determined via CLD and Mayo methods, additional CLD plots, and ${ }^{1} \mathrm{H}$ NMR of the reaction product of citraconic anhydride and dodecanethiol. This material is available free of charge via the Internet at http://pubs.acs.org.

\section{AUTHOR INFORMATION}

\section{Notes}

The authors declare no competing financial interest.

\section{ACKNOWLEDGMENTS}

The authors like to thank Prof. Cor Koning and Prof. Bert Klumperman for useful discussions. This work is part of the research programme of the Dutch Polymer Institute DPI, Eindhoven, The Netherlands, Project No. 651. M.L.C. gratefully acknowledges generous allocations of supercomputing time on the National Facility of the Australian National Computational Infrastructure, funding from the Australian Research Council (ARC) under its Centres of Excellence program and an ARC Future Fellowship.

\section{REFERENCES}

(1) Maeda, H. Adv. Drug Delivery Rev. 2001, 46 (1-3), 169-185.
(2) Klumperman, B. Polym. Chem 2010, 1 (5), 558-562.

(3) (a) Tsuchida, E.; Tomono, T. Makromol. Chem. 1971, 141 (1), 265-298. (b) Deb, P. C.; Meyerhoff, G. Polymer 1985, 26 (4), 629635. (c) Dodgson, K.; Ebdon, J. R. Eur. Polym. J. 1977, 13 (10), 791797. (d) Sanayei, R. A.; O'Driscoll, K. F.; Klumperman, B. Macromolecules 1994, 27 (20), 5577-5582. (e) Fukuda, T.; Kubo, K.; Ma, Y.-D. Prog. Polym. Sci. 1992, 17 (5), 875-916.

(4) (a) Lessard, B.; Maric, M. Macromolecules 2010, 43 (2), 879-885. (b) Wang, Y.; Shen, Y.; Pei, X.; Zhang, S.; Liu, H.; Ren, J. React. Funct. Polym. 2008, 68 (8), 1225-1230. (c) Benoit, D.; Hawker, C. J.; Huang, E. E.; Lin, Z.; Russell, T. P. Macromolecules 2000, 33 (5), $1505-1507$.

(5) (a) Chernikova, E.; Terpugova, P.; Bui, C.; Charleux, B. Polymer 2003, 44 (15), 4101-4107. (b) van den Dungen, E. T. A.; Rinquest, J.; Pretorius, N. O.; McKenzie, J. M.; McLeary, J. B.; Sanderson, R. D.; Klumperman, B. Aust. J. Chem. 2006, 59, 742-748. (c) McLeary, J. B.; Calitz, F. M.; McKenzie, J. M.; Tonge, M. P.; Sanderson, R. D.; Klumperman, B. Macromolecules 2004, 37 (7), 2383-2394. (d) McLeary, J. B.; Calitz, F. M.; McKenzie, J. M.; Tonge, M. P.; Sanderson, R. D.; Klumperman, B. Macromolecules 2005, 38 (8), 3151-3161. (e) Du, F.-S.; Zhu, M.-Q.; Guo, H.-Q.; Li, Z.-C.; Li, F.M.; Kamachi, M.; Kajiwara, A. Macromolecules 2002, 35 (17), 67396741.

(6) (a) Davis, T. P.; Kukulj, D.; Haddleton, D. M.; Maloney, D. R. Trends Polym. Sci. 1995, 3 (11), 365-373. (b) Gridnev, A. A.; Ittel, S. D. Chem Rev 2001, 101 (12), 3611-3659. (c) Heuts, J. P. A.; Roberts, G. E.; Biasutti, J. D. Aust. J. Chem. 2002, 5, 381. (d) Heuts, J. P. A.; Smeets, N. M. B. Polym. Chem. 2011, 2, 2407-2423. (e) Slavin, S.; McEwan, K.; Haddleton, D. M. Cobalt Catalyzed Chain Transfer Polymerization. In Polymer Science: A Comprehensive Reference; Matyjaszewski, K., Möller, M., Eds.; Elsevier BV: Amsterdam, 2012; Vol. 3, Chapter 10.

(7) Adamsons, K.; Blackman, G.; Gregorovich, B.; Lin, L.; Matheson, R. Prog. Org. Coatings 1997, 34 (1-4), 64-74.

(8) (a) Chiu, T. Y. J.; Heuts, J. P. A.; Davis, T. P.; Stenzel, M. H.; Barner-Kowollik, C. Macromol. Chem. Phys. 2004, 205 (6), 752-761. (b) Kukulj, D.; Heuts, J. P. A.; Davis, T. P. Macromolecules 1998, 31 (18), 6034-6041.

(9) (a) Bakac, A.; Brynildson, M. E.; Espenson, J. H. Inorg. Chem. 1986, 25 (23), 4108-4114. (b) Suddaby, K. G.; Haddleton, D. M.; Hastings, J. J.; Richards, S. N.; O’Donnell, J. P. Macromolecules 1996, 29 (25), 8083-8091. (c) American Polymer Standards Corporation www.ampolymer.com (accessed in July 2012). (d) Endo, R. J. Polym. Sci., Part A2 1968, 6, 665.

(10) Frisch, M. J.; Trucks, G. W.; Schlegel, H. B.; Scuseria, G. E.; Robb, M. A.; Cheeseman, J. R.; Scalmani, G.; Barone, V.; Mennucci, B.; Petersson, G. A.; Nakatsuji, H.; Caricato, M.; Li, X.; Hratchian, H. P.; Izmaylov, A. F.; Bloino, J.; Zheng, G.; Sonnenberg, J. L.; Hada, M.; Ehara, M.; Toyota, K.; Fukuda, R.; Hasegawa, J.; Ishida, M.; Nakajima, T.; Honda, Y.; Kitao, O.; Nakai, H.; Vreven, T.; Montgomery, J., J. A.; Peralta, J. E.; Ogliaro, F.; Bearpark, M.; Heyd, J. J.; Brothers, E.; Kudin, K. N.; Staroverov, V. N.; Kobayashi, R.; Normand, J.; Raghavachari, K.; Rendell, A.; Burant, J. C.; Iyengar, S. S.; Tomasi, J.; Cossi, M.; Rega, N.; Millam, N. J.; Klene, M.; Knox, J. E.; Cross, J. B.; Bakken, V.; Adamo, C.; Jaramillo, J.; Gomperts, R.; Stratmann, R. E.; Yazyev, O.; Austin, A. J.; Cammi, R.; Pomelli, C.; Ochterski, J. W.; Martin, R. L.; Morokuma, K.; Zakrzewski, V. G.; Voth, G. A.; Salvador, P.; Dannenberg, J. J.; Dapprich, S.; Daniels, A. D.; Farkas, Ö.; Foresman, J. B.; Ortiz, J. V.; Cioslowski, J.; Fox, D. J. Gaussian 09, Revision C.1; Gaussian, Inc.: Wallingford CT, 2009.

(11) Werner, H.-J.; Knowles, P. J.; Lindh, R.; Manby, F. R.; Schütz, M.; Celani, P.; Korona, T.; Rauhut, G.; Amos, R. D.; Bernhardsson, A.; Berning, A.; Cooper, D. L.; Deegan, M. J. O.; Dobbyn, A. J.; Eckert, F.; Hampel, C.; Hetzer, G.; Lloyd, A. W.; McNicholas, S. J.; Meyer, W.; Mura, M. E.; Nicklass, A.; Palmieri, P.; Pitzer, R.; Schumann, U.; Stoll, H.; Stone, A. J.; Tarroni, R.; Thorsteinsson, T. MOLPRO, a package of ab initio programs, see http://www.molpro.net. 
(12) (a) Coote, M. L.; Lin, C. Y.; Beckwith, A. L. J.; Zavitsas, A. A. Phys. Chem. Chem. Phys. 2010, 12 (33), 9597-9610. (b) Coote, M. L. J Phys Chem A 2004, 108 (17), 3865-3872.

(13) (a) Coote, M. L.; Wood, G. P. F.; Radom, L. J Phys Chem A 2002, 106 (50), 12124-12138. (b) Gomez-Balderas, R.; Coote, M. L.; Henry, D. J.; Radom, L. J Phys Chem A 2004, 108 (15), 2874-2883.

(14) Henry, D. J.; Sullivan, M. B.; Radom, L. J. Chem. Phys. 2003, 118 (11), 4849-4860.

(15) Heuts, J. P. A.; Forster, D. J.; Davis, T. P. ACS Symp. Ser. 2000, No. 760, 254.

(16) Chiefari, J.; Jeffery, J.; Krstina, J.; Moad, C. L.; Moad, G.; Postma, A.; Rizzardo, E.; Thang, S. H. Macromolecules 2005, 38 (22), 9037-9054.

(17) Junkers, T.; Barner-Kowollik, C. J. Polym. Sci., Part A: Polym. Chem. 2008, 46, 7585.

(18) (a) Shaik, S.; Shurki, A. Angew. Chem., Int. Ed. 1999, 38 (5), 586-625. (b) Pross, A.; Yamataka, H.; Nagase, S. J. Phys. Org. Chem. 1991, 4 (3), 135-140.

(19) (a) Heuts, J. P. A.; Davis, T. P.; Russell, G. T. Macromolecules 1999, 32 (19), 6019-6030. (b) Heuts, J. P. A.; Kukulj, D.; Forster, D. J.; Davis, T. P. Macromolecules 1998, 31 (9), 2894-2905. (c) Suddaby, K. G.; Maloney, D. R.; Haddleton, D. M. Macromolecules 1997, 30 (4), $702-713$.

(20) Moad, G.; Moad, C. L. Macromolecules 1996, 29 (24), 77277733

(21) (a) Clay, P. A.; Gilbert, R. G. Macromolecules 1995, 28 (2), 552-569. (b) Whang, B. C. Y.; Ballard, M. J.; Napper, D. H.; Gilbert, R. G. Aust. J. Chem. 1991, 44 (8), 1133-1137.

(22) (a) Soeriyadi, A. H.; Li, G.-Z.; Slavin, S.; Jones, M. W.; Amos, C. M.; Becer, C. R.; Whittaker, M. R; Haddleton, D. M.; Boyer, C.; Davis, T. P. Polym. Chem. 2011, 2 (4), 815-822. (b) Slavin, S.; Khoshdel, E.; Haddleton, D. M. Polym. Chem. 2012, DOI: 10.1039/ C2PY20040F. (c) Zhang, Q.; Slavin, S.; Jones, M. W.; Haddleton, A.

J.; Haddleton, D. M. Polym. Chem. 2012, 3 (4), 1016-1023.

(d) Nurmi, L.; Lindqvist, J.; Randev, R.; Syrett, J.; Haddleton, D. M. Chem. Commun. 2009, 19, 2727-2729. (e) Jones, M. W.; Mantovani, G.; Ryan, S. M.; Wang, X. X.; Brayden, D. J.; Haddleton, D. M. Chem Commun 2009, 35, 5272-5274. (f) Li, G.-Z.; Randev, R. K.; Soeriyadi, A. H.; Rees, G.; Boyer, C.; Tong, Z.; Davis, T. P.; Becer, C. R.; Haddleton, D. M. Polym. Chem. 2010, 1 (8), 1196-1204. (g) Chan, J. W.; Hoyle, C. E.; Lowe, A. B.; Bowman, M. Macromolecules 2010, 43 (15), 6381-6388. (h) Lowe, A. B. Polym. Chem. 2010, 1 (1), 17-36.

(23) Tasdelen, M. A. Polym. Chem. 2011, 2, 2133.

(24) Nagai, K.; Yonezawa, H. J. Polym. Sci., Polym. Lett. Ed. 1983, 21 (2), 115-121.

(25) Das, V. K. Synlett 2011, 3, 430.

(26) Yamada, B.; Zetterlund, P. B.; Sato, E. Prog. Polym. Sci. 2006, 31 (10), 835-877. 